\title{
Um estudo de caso: a vitrine da sala do Sarau.
}

Fabiane Rodrigues Moraes;

Curso de Pós-graduação em Memória Social e Patrimônio

Cultural

rmconservacaoerestauro@gmail.com

Prof $^{0}$ Dr. Diego Lemos Ribeiro; Curso de Pós-graduação em Memória Social e Patrimônio

Cultural

drmuseolog@yahoo.com.br

Prof $^{\circ}$ Dr Thiago Seviliano Puglieri, Curso de Pós-graduação em Memória Social e Patrimônio

Cultural tspuglieri@gmail.com

\section{RESUMO}

Os artefatos têxteis em estudo apresentam um comprometimento estrutural, estando em péssimo estado de conservação. Esses desgastes foram causados pela falta de ações e planejamento de manutenção e conservação do acervo textil composto de cinco conjuntos de saia e jaqueta, exposto a mais de vinte anos na sala denominada "sarau" no Museu Municipal Parque da Baronesa, Pelotas/RS.

Mediante a situação exposta, coube à equipe do museu encontrar uma solução para esses objetos. Mesmo que traga prejuízo à exposição, a provável solução será a retirada e guarda das peças. Planejar a retirada ou a permanência do acervo traz a tona questões de preservação e gestão, pois, como um objeto sob responsabilidade de um museu pode ficar tanto tempo exposto as intempéries? Essas questões são fundamentais para a valorização desse acervo, principalmente por se encontrar em vitrine por tanto tempo e não apresentar histórico próprio, apenas compondo um cenário

Palavras-chave: têxtil; objeto; biografia; política de acervo; resto. 


\section{INTRODUÇÃO}

O presente trabalho trata da conservação do acervo têxtil composto de cinco conjuntos de saia e jaqueta, exposto há mais de vinte anos na sala denominada "sarau" no Museu Municipal Parque da Baronesa, Pelotas/RS.

As indumentárias em estudo apresentam um comprometimento estrutural, estando em péssimo estado de conservação. Em face de uma política descontinuada de coleções, uma realidade presente em parte dos museus brasileiros na atualidade, como proceder, numa tomada de decisão frente a esse problema e compreender como a política de acervos, ou a ausência dela, interfere na conservação dos acervos de museu.

Danos estruturais, esmaecimento, enfraquecimento das fibras do tecido foram causados pela excesso de exposição e falta de planejamento institucional, a que denominamos política de acervos. Compreendemos esse conceito como os parâmetros que orientam as formas de aquisição, proteção e utilização de acervos em uma instituição (PADILHA, 2014). Segundo Ladkin, "uma tomada de decisão eficaz fundamenta-se numa política eficaz. Por essa razão, o documento mais importante do acervo do museu é a Política de Gestão do Acervo" (LADKIN, 2004, p.18).

E por muito tempo essa conservação ficou apenas no passar o pincel, só que as escolhas feitas pela equipe durante esse anos provocaram danos irreversíveis, que será tratado mais tarde. Afinal toda trajetória dessas peças fazem delas portadoras de uma memória.

Os objetos podem servir como narradores e como fonte de estudos da nossa história ou de um grupo, são ferramentas que auxiliam na construção da nossa identidade e da nossa imagem. O que dizer sobre os objetos mais íntimos que nos seres humanos inventamos a roupa, ela nos protege das temperaturas, escondes nossos corpos nus, e durante muito tempo foi sinônimo de status.

As vestes servem para moldar nossos corpos, evidenciam classes sociais,e nelas deixamos nossas marcas. Os objetos possuindo uma biografia, é possível fazer então um retrospecto dessa biografia, como apresenta Meneses (1998, p. 93) posteriormente "a biografia dos objetos introduz um novo problema: a biografia das pessoas nos objetos".

Entender a biografia de alguém através dos objetos faz destes objetos, objetos biográficos e narradores, capazes de narrar a história de alguém e as suas memórias, podendo ao mesmo tempo ser entendidos como objetos documento, biográficos, narradores e suportes de memória. Assim, entende-se que os objetos podem detentores 
de uma "biografia cultural" (KOPYTOFF, 1986), termo que criado por Kopytoff que segundo Gonçalves (2007, p. 24) resume essa carga histórica e memorial dos objetos. Sobre essa ligação íntima entre sujeito e objeto e as memórias que estão presentes nessa relação, Anette Weiner (apud Gonçalves, op. cit., p. 26) destaca:

\begin{abstract}
[...] usamos objetos para fazer declarações sobre nossa identidade, nossos objetivos, e mesmo nossas fantasias. Através dessa tendência humana a atribuir significados aos objetos, aprendemos desde tenra idade que as coisas que usamos veiculam mensagens sobre quem somos e sobre quem buscamos ser. [...] Através dos objetos fabricamos nossa auto-imagem, cultivamos e intensificamos relacionamentos. Os objetos guardam ainda o que no passado é vital para nós. [...] não apenas nos fazem retroceder no tempo como também tornam-se os tijolos que ligam o passado ao futuro
\end{abstract}

Se o objeto pode ser entendido como um documento, e como fonte de pesquisa para o historiador, Meneses (1998, p. 92) diz que "o cerne da questão, para o historiador [...] é, acredito, que os artefatos estão permanentemente sujeitos a transformações de toda espécie, em particular de morfologia, função e sentido, isolada, alternada ou cumulativamente. Isto é, os objetos materiais têm uma trajetória, uma biografia pensamento de Moles (1972) dito anteriormente, onde os objetos são essenciais no nosso mundo e possuem uma grande importância na construção da relação dos indivíduos com o mundo, sociedade, e a sua própria vida cotidiana. Esse papel que o objeto tem faz com que muitas vezes eles sejam vistos pelos seus donos, como uma extensão de si mesmo, como um "extended self” (Meneses, 1998, p. 96). Sobre essa relação dos humanos com seus objetos e desses objetos com a memória e identidade, Bosi destaca:

\footnotetext{
Mais do que uma sensação estética de utilidade eles nos dão um assentimento à nossa posição do mundo, à nossa identidade; e os que estiveram sempre conosco falam à nossa alma em sua língua natal. [...] São estes objetos que Violette Morin chama de objetos biográficos, pois envelhecem como possuidor e se incorporam à sua vida: o relógio da família, o álbum de fotografias, a medalha do esportista [...]. (BOSI, 2005, p. 5).
}

Nesse trecho, Bosi utiliza a classificação de Violette Morin para caracterizar os objetos biográficos como aqueles que fazem parte da vida de alguém, que auxiliam na construção de sua identidade, do seu lugar no mundo. Fazendo a relação entre os objetos e a memória, e estes como suportes de memória, Ferreira (2008) analisa os objetos e a sua relação entre memórias (individuais e coletivas) e a importância deles para a construção da identidade dos mesmos. No artigo intitulado "Objetos, lugares de memória”, a autora analisa contextos importantes, dentre eles, a relação simbólica e o caráter de relíquia que muitos objetos recebem.

\title{
LUGAR DE MEMORIA OU DE ESQUECIMENTO.
}


Com a entrada na instituição em 1989, essa peça passaram a compor, o circuito, dando seqüência ao discurso tendo alterado seu valor de uso, adquirindo um valor simbólico, dando a essas peças uma segunda chance de vida estes contam a historia de uma época em que a cidade de pelotas vivia o apogeu do charque.

Essas peças atingiram uma importância, que estas não foram substituídas, e as explicações são simples, não há peças de reposição o que tornou as peças insubstituíveis, tratando se de volumes não há espaço para guarda em reserva, e com uma mudança teria que ser revista toda monitoria. Essa exposição permanente causou problemas estruturais, e estas estão no final de sua vida útil. Conforme Debary, 2015

\footnotetext{
Um objeto alcança o fim de sua vida de estante quando passa a ser considerado obsoleto, quando seu valor de uso inicial acaba. [...] Às vezes eles se tornam parte de nossa herança oficial (museus), às vezes ficam guardados em sótãos e garagens e às vezes são simplesmente descartados questionamento sobre o poder dos objetos.
}

A partir dessa citação de Octave Debary e tendo como analise esse conjunto de objetos, que estão no museu, onde essa instituição preza pela perpetuação pra gerações futuras, como proceder quando esse objetivo se quebra. Em outros termos, o que devemos ter em uma política de acervos para evitar a degradação das coleções em instituições que, pretensamente, existem para preservá-las.

Visando delimitar o que realmente faz um objeto se tornar um acervo, se um objeto, nasce patrimonializado, ou é pensado por um grupo,ou são determinados por ressonâncias.

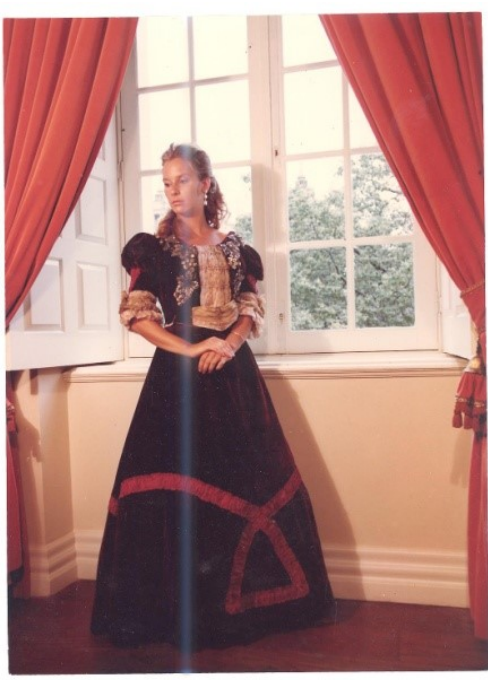

Figura 1. O vestido ainda servindo pra adornar o corpo. Foto pertencente ao acervo museu da Baronesa.

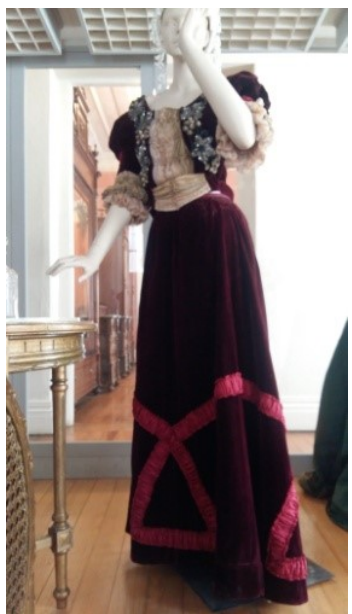

Figura 2. O vestido já em uso patrimonial. Foto.Moraes 
Trataremos desse vestido, que esta em exposição no museu, na primeira foto ele ainda serve ao seu propósito, que é adornar o corpo, na segunda foto este serve de cenário para o sarau.

A trajetória dessa peça começa com dona Marcolina Gonçalves chaves Barcellos, que o usou no casamento de sua filha, dona catita.

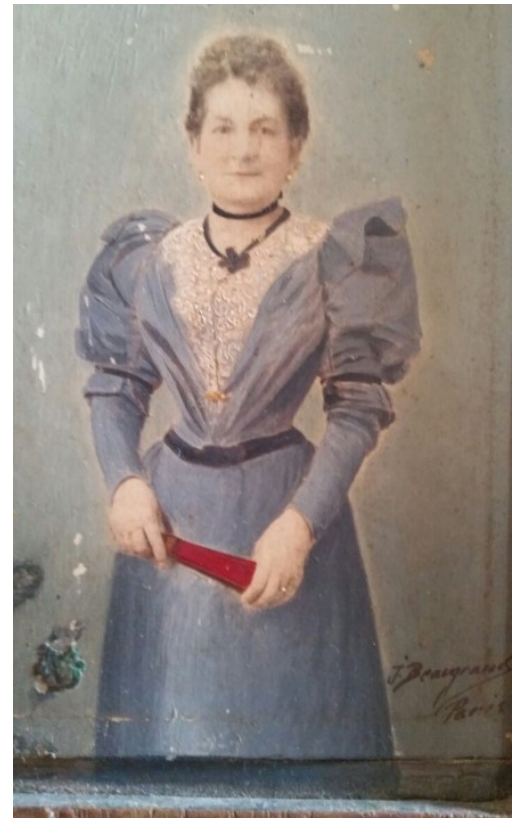

Figura 3. Marcolina Chaves Barcellos. Foto:Maria Rita Sampaio

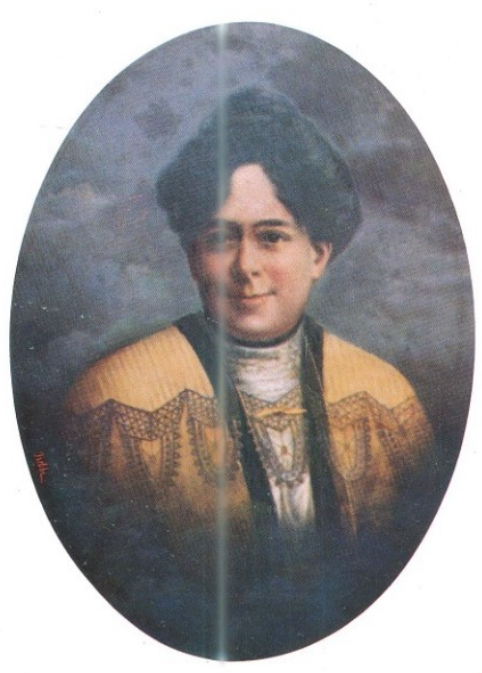

Figura 4. Dona Catita. Foto: acervo Museu da Baronesa.

Dona catita casa se com Edmundo Berchon Des Essarts com o falecimento de sua filha é catita que cuida da neta Antonia Sampaio, e esta herda o vestido de sua bisavó.

- Essas peças foram em 1987-88 restauradas no museu do traje para que pudessem participar da exposição cem anos de trajes no casarão 6 na cidade de Pelotas,no ano de 1989, logo essa exposição foi transferida para o museu da Baronesa .

E nessa trajetória, os vestidos de dona Marcolina repousam no museu da baronesa, visando a eternidade e a contemplação para as gerações futuras. No momento em que as peças encontram no fim de sua vida, é necessária a reflexão, qual o papel do museu para com essas peças, que serviram por tanto tempo ao propósito de adorno e cenário. Starace comenta:

"As transferências de mão implicam uma posse renovada, promovem usos diferentes dos anteriores; lugares, atmosferas, temperaturas, luzes, vozes talvez inimagináveis. E em cada mudança o objeto pode encontrar um novo sentido para existir, é levado a reconstruir a sua historia desde o principio. Os objetos podem ter muitos mais que uma vida, mas é de perguntar se, uma vez transmitido aos novos proprietários, conseguem conservar algum vestígio de sua experiência anterior." (STARACE, pag147, 2015) 


\section{CONCLUSÃO}

Em suma o museu é depositário de inúmeros objetos, muitos nunca terão a oportunidade de sair da reserva técnica, outros tantos farão o caminho inverso e jamais retornaram. Qual a responsabilidade de uma instituição de memória?

Possivelmente essas peças que em um determinado tempo saíram de cena, mesmo que o museu não esteja preparado, pois, as coisas obedeçam a finitude da matéria e somente nesse momento seja possível analisar o que deveríamos ter feito para salvaguardar essas peças.

Enquanto esse momento de morte não chega cabe uma pergunta, o que devemos fazer com um objeto que alcança status de patrimônio e que deixa de servir a esse propósito? Qual o final digno?

\section{REFERÊNCIAS}

BRADLEY, Susan M. Os Objetos têm Vida Finita? S.Keene (org), Care of Collections Leicester reads in Museum Studies. Londres: Routledge, 1994, p.51-59. Mendes, Marilka [ET AL]; tradução Vera L. Ribeiro. IN: Conservação: conceitos e práticas/organização de Rio de Janeiro: editora UFRJ, 2001.

CANDAU, Joël. Memória e Identidade. São Paulo: Contexto, 2012.

Choya, Françoise. A Alegoria do Patrimônio. Tradução de Luciano Vieira MachadoSão Paulo: Estação Liberdade: Editora UNESP, 2001.

Debary, Octave Vendas de garagem: um livro e uma exposição: do descarte de objetos a redenção da memória. Culture Unbound, Volume 7, 2015

GONÇALVES, José Reginaldo Santos. Antropologia dos objetos: coleções, museus e patrimônios / José Reginaldo. Santos Gonçalves. - Rio de Janeiro, 2007.

HALBWACHS, Maurice. A Memória Coletiva. São Paulo: Vértice, 1990.

ICOM.Código de Ética do ICOM para Museus: Versão Lusófona. Goiana UFG, Museu Antropológico, ICOM Brasil,2010.

KOPYTOFF, Igor. 1986. "The cultural biography of things: commoditization as process". In APPADURAI, Arjun, ed. The social life of things.Commodities in cultural perspective. Cambridge, Cambridge University Press, p. 64-94.

LEAL, Nóris Mara Pacheco Martins. Museu da Baronesa: Acordos e conflitos na construção da narrativa de um museu municipal - 1882 a 2004. 2007.

MARTINS, Larissa Tavares. Costurando para a Baronesa: Trabalho e sociabilidade no início do século XX. Capítulo do Livro - Mulheres Trabalhadoras - olhares sobre 
fazeres feminino, 2012.

MENESES, Ulpiano T. Bezerra de. 1996. A psicologia social no campo da cultura material", Anais do Museu Paulista. História e Cultura Material. São Paulo, N. S., 4: $283-90$

PAULA, Teresa Cristina Toledo de. Conservação de Têxteis Históricos: uma bibliografia introdutória. Anais do Museu Paulista. São Paulo. N. Ser. p. 301-319 V.Z jan./dez. 1994

POULOT, Dominique.*Museu e Museologia. Belo Horizonte: Autêntica. Editora, 2013. STARACE, Giovanni. Os objetos e a vida: reflexões sobre as posses, as emoções,a memória/ Giovanni Starace;Tradução Sergio maduro._ São Paulo:Martins fontes- selo Martins,2015 